\title{
Mapping ecosystem services at the regional scale: the validity of an upscaling approach
}

\section{Journal Article}

\section{Author(s):}

Le Clec'h, Solen; Sloan, Sean; Gond, Valéry; Cornu, Guillaume; Decaëns, Thibaud; Dufour, Simon; Grimaldi, Michel; Oszwald, Johan

\section{Publication date:}

2018

\section{Permanent link:}

https://doi.org/10.3929/ethz-b-000261262

\section{Rights / license:}

In Copyright - Non-Commercial Use Permitted

\section{Originally published in:}

International Journal of Geographical Information Science 32(8), https://doi.org/10.1080/13658816.2018.1445256 


\section{Mapping ecosystem services at the regional scale: the validity of an upscaling approach}

Solen Le Clec' $h^{1,2}$, Sean Sloan ${ }^{3}$, Valéry Gond ${ }^{4}$, Guillaume Cornu ${ }^{4}$, Thibaud Decaens ${ }^{5}$, Simon Dufour ${ }^{2}$, Michel Grimaldi ${ }^{6}$ and Johan Oszwald ${ }^{2}$

1. Agricultural Economics and Policy

ETH Zürich, SOL C7

Sonneggstrasse 33

8092 Zürich, Switzerland

Contact:solenle@ethz.ch

2. Université Européenne de Bretagne - Rennes 2

Laboratoire LETG Rennes - COSTEL (UMR CNRS 6554)

Place Henri Le Moal, Rennes, France

3. School of Science and Engineering, Center for Tropical Environmental and Sustainability Science, James Cook University, Cairns, Qld, 4870, Australia.

sean.sloan@jcu.edu.au

4. CIRAD

TA C-105 / D, Campus international de Baillarguet

34398 Montpellier cedex 5, France

5. Centre d'Ecologie Fonctionnelle et Evolutive,

UMR 5175 CNRS / Univ of Montpellier / Univ of Montpellier 3 / EPHE / SupAgro Montpellier / INRA / IRD, 1919

Route de Mende, 34293 Montpellier Cedex 5, France

6. Institut de Recherche pour le Développement (IRD)

UMR 211 BIOEMCO

Centre IRD France-Nord

32, av. H. Varagnat, F-93143 Bondy cedex, France

\section{Corresponding author}

Solen Le Clec'h,

E-mail: ; solenle@ethz.ch

\section{Abstract}

Mapping ecosystem services (ES) over large scales is important for environmental monitoring but is often prohibitively expensive and difficult. We test a hybrid, low-cost method of mapping ES indicators over large scales in Pará State, Brazil. Four ES indicators (vegetation carbon stocks, biodiversity index, soil chemical quality index 
and rates of water infiltration into soil) were measured in the field and then summarized spatially for regional landcover classes derived from satellite imagery. The regionally mapped ES values correlated strongly with independent and local measures of ES. For example, regional estimates of the vegetation carbon stocks are strongly correlated with actual measures derived from field samples and validation data (significant anova test $-p$-value $=4.51^{e-9}$ ) and differed on average by only $20 \mathrm{Mg} / \mathrm{ha}$ from the field data. Our spatially-nested approach provides reliable and accurate maps of ES at both local and regional scales. Local maps account for the specificities of an area while regional maps provide an accurate generalization of a ES' state. Such up-scaling methods infuse large-scale ES maps with localized data and enable the estimation of uncertainty of at regional scales. Our approach is first step towards the spatial characterization of ES at large and potentially global scales.

Keywords: Ecosystem services mapping; Up-scaling; Remote sensing; Soil chemical quality; Soil infiltrability; Biodiversity; Carbon stocks; Brazilian Amazon 


\section{Introduction}

Ecosystem services (ES) has become a key concept in environmental governance following the Millennium Ecosystem Assessment (MEA) in 2005 (Millennium Ecosystem Assessment 2005; Andriamahefazafy et al. 2012; Roche et al. 2016). Quantifying and mapping ES are increasingly important goals of environmental decision making seeking to conserve and enhance ES (Daily and Matson 2008), as by targeting policy in strategic geographical areas or evaluating potential ES impacts of alternative policies (European Commission and Directorate-General for the Environment 2013; McInerny et al. 2014; Grêt-Regamey et al. 2015). To this end, decision makers need reliable and accurate spatial information on the state of various ES at different scales. Local-scale maps of ES provision can be relatively reliable because they can be based on detailed field observations of ecosystem services. Such maps can help facilitate knowledge transfers amongst ES stakeholders, as by facilitating dialogue over the factors and implications of spatial patterns of ES supply (Pagella and Sinclair 2014). The spatial heterogeneity of environmental factors underlying ES provision, such as land use or soil type, makes complex the extrapolation of local ES patterns to regional scales, particularly as the large-scale spatial representations of environmental parameters inevitably entail a diminishment of fidelity (Wilbanks, 2006). However, regional ES maps are required to inform state, national, and global ES targets and environmental-management policies, e.g., The Convention on Biological Diversity. To clarify the uncertainty and utility of regional-scale maps of ES provision, we elaborate and validate a cost-effective regional approach to ES mapping in Brazil.

The spatialization of ES at large scales leads to a loss of information due to three main factors (Wilbanks 2006). First, even if ES are manifest at regional scales (Hein et al. 2006), underlying biophysical processes rely heavily on local processes and practices. Therefore, there is a mismatch between the local scale of the biophysical processes that provide ES and the regional scale of representation, necessitating an approximation with a potentially unknown error component. Such error may arise equally from a coarse resolution of regional observation, as from regional generalizations of finer-resolution observations. For example, the use of satellite imagery with $1-\mathrm{km}^{2}$ resolution may underestimate ES such as the those related to biodiversity conservation insofar as this approach may discount forest fragmentation and/or linear habitats such as along rivers and wetlands (Di Sabatino et al. 2013). Second, the larger the territory of interest, the more difficult and expensive it is to obtain representative, local-scale samples of ES provision over its extent (Sant et al. 2014). Larger territories may therefore rely more on limited local sample data or, alternatively, on coarser regional data, incurring approximation errors in both instances, as noted above. Third, ES mapping approaches tend to greatly simplify underlying local specificities that in turn distort regional depictions of ES, often without understanding of the underlying influencing factors (Fisher et al. 2011). Further, such regional depictions of ES are rarely validated - only 7\% of regional ES estimates were validated according to our review of the literature of 104 peer-reviewed studies entailing regional ES mapping published between 1990 and 2016. These studies were identified within the Web of 
Science database via search criteria requiring the presentation of at least one ES map and that keywords "mapping", "maps" or "ecosystem services" appear in the title, abstract or text of the study. According to this review, $85 \%$ present regional ES maps encompassed study sites of at least $250 \mathrm{~km}^{2}$.

'Up-scaling' processes that transfer existing information from local to regional scales (Pelgrum 2000; Wu and Li 2009) offer a relatively unexplored alternative approach to regional-scale ES mapping. Up-scaling approaches promise relatively low costs and straightforward implementation. Their promise has been highlighted accordingly (Liang 2004; Liu et al. 2016), especially in regards to facilitating environmental management and decision-making (Bierkens, Finke, and Willigeb 2000; Finke, Bierkens, and Willigen 2002; Li et al. 2016). The approach offers several advantages for regional environmental assessments (Lacoste 1976), including a comprehensive survey of the region via nested, spatially- variable ES estimates; reduced mismatch between the scale of biophysical processes underlying ES and the scale at which decisions concerning ES are made; cost-effectiveness; and the possibility of validating regional ES representations. Moreover, one output of up-scaling approach is available information at multiple spatial scales. Yet, the interests of possessing such information are often highlighted (Millennium Ecosystem Assessment 2005; van Jaarsveld et al. 2005). The fidelity of any upscaling approach ultimately depends on the density and quality of local data but also critically on the spatial variability of ES supply.

Here we outline a methodology that describe potential ES supply at the regional scale despite the limited availability of local-scale ES data. Specifically, for Pará State, Brazil, we elaborate and validate an 'up-scaling' approach that extrapolates information on ES supply from local to regional scales in order to map and quantify ES regionally. Section two outlines our methodology. Section three assesses our approach by comparing regional ES estimates with independent, local measures across Pará. It especially presents a three-fold validation of our regional maps: a field data-based validation, a local map-based validation and a calculation and map of the variability of ES values within the land-cover classes. Section four discusses the implications of our results.

\section{Methodology}

\subsection{Overview}

We tested the reliability of an up-scaling approach by comparing its regional-scale estimates of ES potential supply against independent local ES measures. We based our approach on the landcover classification because the MEA (2005) assured that land-cover changes greatly impact ES supply in general. Previous studies confirmed this tendency for the ES that are studied in this paper (Le Clec'h et al. 2017). 
Our methodology is characterized by three major steps (Figure 1) based on field measures of four key indicators of ES supply (forest carbon stocks [ES of climate regulation], rates of water infiltration into soil [water regulation], soil chemical quality index [soil conservation], and species richness index [biodiversity]) from 135 plots across Pará State, Brazil (within AMAZ research programs). First, we spatially summarized (average and standard deviation) the plotlevel ES data according to coincident land-cover classes derived from localized Landsat imagery classifications. Second, we integrated these summary values (average value for the ES assessment and standard deviation for the uncertainty assessment) with a regional MODIS landcover classification. Local field measures of the four ES were thus fused with consistent local and regional land-cover classifications to spatially extrapolate field measures to the regional level. Third, we validated the resultant regional ES maps by comparing their values to independent as well as locally-predicted ES datasets.

\section{Figure 1}

\subsection{Study Context}

Pará State of the Brazilian Amazon forest is a global hotspot of ES provision (Fearnside 2005) (Figure 2). Pará spans 1.25 million $\mathrm{km}^{2}$, which are partly covered by tropical forest. Extensive forests, high biodiversity and rapid deforestation qualify Pará as indicative of contexts in which rapid, large-scale ES surveys are most urgently required. Forests in Pará have experienced rapid deforestation over recent decades, mainly for timber and cattle (Fearnside 2008; Godar, Tizado, and Pokorny 2012), with $1887 \mathrm{~km}^{2}$ deforested in 2014 (INPE Prodes 2014). While deforestation has been slowing, the area deforested in Pará in 2013 still accounted for almost half of total deforestation in Brazil (INPE Prodes 2014).

\section{Figure 2}

Within Pará we undertook field measures of ES within three study sites indicative of regional variations in socio-economics, deforestation histories, and ES change (Figure 2). The first site, Maçaranduba, covers $220 \mathrm{~km}^{2}$ in the municipality of Nova Ipixuna. Deforestation there began relatively early in the 1970s. Although largely deforested, its remaining forest is relatively well preserved. The second site, Pacajá, is located on one of the major arterial 'fishbone' roads (Traverssão 338 South) of the Trans-Amazon highway. It spans $175 \mathrm{~km}^{2}$ and is $60 \mathrm{~km}$ from Pacajá urban center of Pacajá. Spontaneous agricultural colonization commenced there in 1990 and converted the landscape to pasture as well as annual and perennial crops. Forest cover occupied $63 \%$ of this site as of 2007. The third site, Palmares II, is an assentamento (settlement) of $160 \mathrm{~km}^{2}$ near the Carajas iron mine. This site, emblematic of the agrarian reform, was established following conflict between Landless Workers' Movement, the federal government and the Vale mining company. After the land was conceded to the workers it was distributed as 
lots, provoking considerable forest fragmentation. In 2007 , forest cover occupied $23 \%$ of the site.

As described below, field data from these three sites were sampled to either calibrate or validate our regional ES estimates. Additional validation data from a fourth site, Benfica, was also used. This site is geographically very close to Maçaranduba. It belongs to the municipio of Itupiranga, $70 \mathrm{~km}$ from the Transamazonian highway. Its climate and vegetation are comparable to those of the other sites. Its landscape, composed of a mosaic of forests and pastures, is mostly grazed (Coelho, Miranda, and Mitja 2012).

\subsection{Ecosystem Service Data and Regional Mapping}

\subsubsection{Field Data: Indicators of Ecosystem Services Potential Supply}

Field data on the potential provision of the four key ES were collected over 135 sample plots between 2008 and 2011 in the four sites described previously. These sample plots spanned 27 farms, with nine farms in each of the three study sites. In each farm five sample plots were spaced in equal distances along a transect corresponding either to the longest diagonal of the farm or to a north-south axis. Transects intersected all major land covers in the region, including disturbed and intact forests, and had an average length of $1 \mathrm{~km}(\mathrm{~min}=815 \mathrm{~m}, \max =1163$ and $\mathrm{sd}$ $=76.8 \mathrm{~m})$.

Each sample plot entailed measures of four biophysical measures indicative of ES provision (Table 1). Measures of vegetation carbon stock, soil water infiltration rate, soil chemical composition, and species richness are respectively taken as indicative of atmospheric carbon density (historic sequestration), water provision, soil conservation, and biodiversity. The indicators were calculated as follows (for more details, see Grimaldi et al. (2014):

Vegetation Carbon Stocks: Aboveground dry plant biomass of trees [BT: diameter at breast height $(\mathrm{dbh}) \geq 10 \mathrm{~cm})$ ] and bushes (BB: $\mathrm{dbh}<10 \mathrm{~cm}$ and height $>2 \mathrm{~m}$ ) was estimated by applying allometric equations for forests (Gerwing 2002; Higuchi et al. 1998) and fallows (Nelson et al. 1999) after identifying species and measuring the diameter and height of individuals on plots of $50 \times 10 \mathrm{~m}^{2}$ and $50 \times 5 \mathrm{~m}^{2}$, respectively. Water content was calculated at $70^{\circ} \mathrm{C}$ with corresponding biomass aliquots (all individuals with $\left.\mathrm{dbh} \leq 5 \mathrm{~cm}\right)$, or otherwise $(\mathrm{dbh}>$ $5 \mathrm{~cm}$ ) applying the factor 0.603 according to Higuchi et al. (1998). In the absence of carbon analysis of plant samples, carbon mass was estimated as $50 \%$ of dry plant biomass (Markewitz et al. 2004).

Soil Water Infiltration Rate: Using the infiltration Beerkan test (Lassabatere et al. 2006), we calculated the infiltration rate of a water volume of $250 \mathrm{~cm}^{3}$ poured into a ring of $20 \mathrm{~cm}$ diameter inserted $1 \mathrm{~cm}$ into the soil surface. This infiltration test was repeated four times and the average value was taken as the datum for analysis. 
Soil Chemical Quality: Soil chemical properties of the $0-10 \mathrm{~cm}$ soil horizon were determined as a composite from two pits per plot. Eight chemical properties were surveyed : $\mathrm{pH}, \mathrm{H}_{2} \mathrm{O}$, cation exchange capacity (CEC) at soil $\mathrm{pH}$, exchangeable $\mathrm{Al}^{3+}, \mathrm{Ca}^{2+}, \mathrm{Mg}^{2+}$ and $\mathrm{K}^{+}$, exchangeable $\mathrm{NH}_{4}{ }^{+}$ and extractable phosphorus using standard methods (Pansu and Gautheyrou 2006). A normalized PCA implemented on these properties allowed the determination of a soil chemical quality index as the first principal component (Grimaldi et al. 2014; Marichal et al. 2014; Velasquez, Lavelle, and Andrade 2007).

Species Richness: At each plot we recorded the number of species for 12 different groups of fauna and flora (moths, birds, bees, fruit flies, ground spiders, ants, termites, earthworms, other soil macro-invertebrates, and vegetation at lower, middle and upper canopy strata). The species richness of each group was normalized as a proportion of the highest richness observed for that group across the 135 sample plots. A generalized index of species richness per plot was in turn calculated as the mean of the normalized proportions across the 12 groups. The generalized index ranges from 0 (species richness in each group is nil) to 1 (species richness in each group is the maximum observed).

\section{Table 1}

\subsubsection{Remote-Sensing Data: Extrapolations of Field Measures to the Regional Scale}

To map ES regionally we employed a two-stage spatial extrapolation uniting the plot-level measures with local, high-resolution Landsat satellite imagery and subsequently with regional, moderate-resolution MODIS satellite imagery (Figure 1). The local high-resolution imagery was used in a previous study to map the four ES indicators considered here (Le Clec'h et al. 2017). In the first stage, we measured the average and standard deviation of plot-level ES measures for our three main field sites (Maçaranbuda, Pacajá and Palmares II) according to coincident landcover classes of three localized, Landsat TM classifications (30-m resolution). The Landsat classifications were produced by supervised maximum-likelihood classifications of six landcover classes (forest, burned forest, fallow lands, grasslands with trees, clean grasslands and bare soils) as of 2007. Training data used for the supervised classification were sampled during field campaigns. Landsat images were radiometrically and geometrically corrected prior to classification to ensure comparability across Para.

In the second stage, we transferred ES measures for the Landsat land-cover classes to corresponding land-cover classes of the regional moderate-resolution MODIS classification for 2007 spanning Pará. Our regional classification was based on MODIS Enhanced Vegetation Index (EVI) 16-day composite images (MOD13Q1c5). To reduce noise associated with atmospheric effects, MODIS EVI images for 2006 and 2007 were averaged (Pennec et al., 2011). An unsupervised ISODATA classification method (Ball and Hall, 1965) was applied to the averaged EVI data, resulting in three general land-cover classes (forest; mosaics dominated by degraded forests and secondary vegetation, hereafter termed transition areas; and mosaics 
dominated by agricultural areas hereafter termed agricultural areas). Other land-cover classes could not be readily discriminated since their spectral signals were insufficiently distinct or their spatial footprints too minor. In addition, Pará State has more land-cover types than our local field study sites (e.g. savannas or wetlands). Thus, our regional classification present also includes four additional, relatively spatially-confined mosaic land-cover classes for which we cannot associate an ES value, namely wetlands, hydromorphic soils and mosaics of low vegetation and bare soil. The six classes of the Landsat classification were collapsed into the three classes of interest of the MODIS classification. Landsat forest areas were collapsed into forest areas. Landsat burned forests and fallow lands were collapsed into "transition areas". Pastures with trees, cleaned pastures and bare soils that were discriminated with Landsat were collapsed into "agricultural areas". The ES values of the original Landsat classes were averaged for the corresponding MODIS classes, resulting in our regional ES maps.

The MODIS land-cover classification was tested through visual and statistical analyses of 150 random points at which the agreement between this classification and the three local (Landsat) land-cover maps was assessed. A chi-square test of agreement was significant $\left(\chi^{2}=266\right.$ and pvalue $<0.001$ ), as corroborated a 'class confusion matrix' integrating the MODIS and Landsat classifications (Table 2).

\section{Table 2}

\subsection{Regional ES Map Validation}

We assessed the regional maps of our four key ES by comparing their ultimate regional values against independent as well as locally-predicted, spatially-explicit measures of ES provision. Three such comparisons were undertaken, detailed below.

In the first, we compared the regionally-mapped ES values to those of various, independent datasets of ES potential supply (Table 3). Specifically, for vegetation carbon stocks we evaluated the agreement between our regional values and the estimated values of Baccini et al. (2012), which entailed locally-intensive LiDAR observations linked with field measurements. For regional soil water infiltration rates and our biodiversity index, we randomly split our 135 sample plots into training and validation datasets. The training dataset was used to generate regional ES maps as detailed above, while the validation dataset was used to evaluate their agreement with locally-observed values. For regional soil chemical quality index, we compared our regionallymapped values to 47 sample plots from our fourth field site of Benfica, Pará (Figure 2), which was not used to generate the regional ES estimates.

\section{Table 3}

In the second comparison, we compared our regional ES estimates to maps of locally-modelled values of the corresponding ES indicators for the Maçaranduba, Pacajá, and Palmares II sites (Le 
Clec'h et al. 2017). These local ES values were predicted using competitive statistical models that linked the sample ES data from the 135 plots with various high-resolution remote-sensing data, e.g., vegetation cover, topography. In this previous study, we based the validation of the map on a confrontation between the ES observed values (135 sampling points) and the values predicted by the regression models. We thus used the $\mathrm{R}^{2}$ to assess the goodness of fit of our models. To observe the agreement between these locally-predicted values and our regional estimates of ES supply, we randomly selected 180 MODIS pixels from across the three study sites, compared their regional ES value to the locally-predicted values (Le Clec'h et al. (2017), and calculated a Chi-Square statistic to test for significant differences between them.

Finally, we calculated the variability of plot-level measures of each of the four ES within the regional land-cover classes. To do so, for each regional land-cover class, we calculated the standard deviation of all coincident plot-level ES measures. Since, the standard deviation value of a metric is dependent on its unit of measure, we standardized the standard deviation to facilitate comparison of the variability amongst the four ES indicators. This analysis indicates the variability and thus the predictive uncertainty associated with the regional ES maps.

\section{Results}

\subsection{Validation of Regional ES Maps Against Independent ES Datasets}

Comparisons of the regionally-estimated ES values against the independent datasets (Table 3) are favourable but mixed. Of the four ES indicators, three (vegetation carbon stocks, soil water infiltration rates, and the soil chemical quality index) show similar trends between the regionallyestimated values and values from the independent validation datasets (Figure 3). For these three ES indicators, average discrepancies with these validation data are $83 \mathrm{Mg} / \mathrm{ha}, 66 \mathrm{~mm} / \mathrm{h}$ and 0.1 , respectively. In contrast, regional estimates for the species richness ES indicator validated poorly against the local, independent measures (Figure 3). The separation of the species richness index values between our regional 'transition' and 'forest' land-cover classes was much less for the regional estimates than for the plot-level data (Figure 3). For all four ES indicators, separate ANOVA tests confirmed significant differences $(\mathrm{p}<0.001)$ between the means and standard deviations amongst our regional land-cover classes.

\section{Figure 3}

\subsection{Validation of Regional ES Maps Against Local ES Maps}

For the same three of our four ES indicators (vegetation carbon stocks, soil water infiltration rates, and the soil chemical quality index), we also observed a strong agreement between regionally-estimated ES values and those predicted locally according to models referencing plotlevel data (Le Clec'h et al. (2017) $-\chi^{2}$ test, $p<0.01$ - Figure 4.a). As for the comparisons between regionally-estimated ES values and our independent ES measures of Figure 3, estimates for the species richness index exhibited a lack of consistency between the regional and local maps (visual interpretation of Figure 4.b.). The uncertainty of locally-predicted ES values resulting 
field measures and models present a degree of uncertainty to these comparisons. This uncertainty is approximated by the $\mathrm{R}^{2}$ coefficient of the accuracy of locally-predicted ES values, which varies amongst the ES indicators. For example, the locally-predicted soil water infiltration rates have a $\mathrm{R}^{2}$ of 0.57 , compared to vegetation carbon stocks map at $\mathrm{R}^{2}=0.75$. Nonetheless, as the $\mathrm{R}^{2}$ value for the species richness index is reasonably high, at 0.71 , the assertion that the regional estimates of species richness capture locally-modelled patterns poorly can be made with some confidence.

Despite the agreement between the ES maps between regional and local scales, the regional maps inevitably entail a simplification of ES patterns compared to local-scale maps (Figures 4; Le Clec'h et al. 2017). The number of regionally-estimated ES values (three per ES indicator) is less, and sometimes much less, than for locally-predicted values (five in the case of the indicator with the smallest number - Figures 4). Correspondingly, for three ES indicators (species richness index, soil water infiltration rates, and soil chemical quality index), the range of regional values is also less than at the local scale, largely because the maximal regional values are 'averaged down' at the expense of local specificities, including those specific to individual field sites (maximal regional values respectively $24 \%, 25 \%$ and $41 \%$ lower than the maximal local values - Figures 3 and 4). Therefore, although the magnitudes of regionally-estimated values correspond with the locally-predicted values on a class-by-class basis (Figures 4), there remain discrepancies not only between these class values but also and perhaps especially between locally-extreme and regionally-observed values. For all ES indicators, differences between regional values and locally-predicted values were significant (ANOVA tests). Hence, regionally-estimated values should be considered as orders of magnitude, not as precise measures.

\section{Figure 4.a}

\section{Figure 4.b}

According these preliminary results, we mapped three out of the four ES indicators (vegetation carbon stocks, soil water infiltration rates, the soil chemical quality index) across the entire state of Pará (Figures 5.a. and 5b.). The distribution of ES values across the regional land-cover classes is generally as expected, with ES values typically highest for forest, intermediate for transition areas, and lowest for grasslands. However, it is noteworthy that both local and regional estimates of the soil quality index reflect an inverse pattern (Figure 3,5b) since soils are chemically poorer under forest cover and become richer when area is deforested (Grimaldi et al. 2014).

Figure 5.a.

Figure 5.b. 


\section{Discussion}

We mapped three ES indicators (vegetation carbon stocks, rates of water infiltration into soil and soil chemical quality) at a local and a regional spatial scale to assess the reliability of regional ES mapping approaches extrapolating localized ES field data. In general, our results cautiously recommend this approach to regional ES mapping, finding for example a strong agreement between regionally-estimated, locally-predicted and independent measures of ES for three of our four key ES indicators (Figures 3, 4 and 5). Up-scaling approaches such as the one outlined here offer ready solutions to many of the issues that typically beset large-scale spatially-explicit estimates of environmental values. Firstly, such approaches afford opportunity of enhancing regional-scale representations of ES spatial distributions via local-scale maps capturing local variations in ES supply. Second, such approaches enable tests of the reliability of regional ES estimates using statistical analyses linked to local data. Thus, our regional estimates stand in contrast to other common, multi-scale approaches such as InVEST, based on globally-calibrated data of dubious relevance for any given regional application (Swetnam et al. 2011).

However, our results also highlight a markedly unequal amenity towards reliable regional extrapolation amongst our ES indicators. This unequal amenity is attributable to two factors. On the one hand, for our species richness index poor agreement was observed between regional ES estimates and the independent local data (Figure 3). This suggests a loss of fidelity of ES representations as they were scaled to regional levels; however, the simple possibility of incompatibility of our regional data and the independent local estimates cannot be discounted. On the other hand, unequal amenity is also reflected in the locally-predicted ES values, as indicated by the considerably greater reliability of ES values for carbon stock $\left(\mathrm{R}^{2}=0.75\right)$ and soil chemical quality index $\left(\mathrm{R}^{2}=0.67\right)$ than for soil water infiltration $\left(\mathrm{R}^{2}=0.57\right)$. Accordingly, our validation of regional-scale map of soil water infiltration rates using locally-predicted-ES estimates may be relatively less reliable. This highlights how the best practice for up-scaling approaches such as ours must entail not only validations of the regional estimates, but also assessments of the local-scale ES data by which regional estimates are derived and validated.

One strength of our study rely on the three-fold validation of our regional maps (Table 4). The field data-based validation allows us to get information about the general accuracy of our regional assessment. The local map-based validation allows us relies on a visual verification of the agreement, in terms of values and spatial structures, of our regional maps with local maps based on more data and on data-driven methods. Finally, the calculation and map of the variability (standard deviation) highlights the needs for further research, for it underlines the limitation of the use of our land-cover data to extrapolate ES values. As this last validation only presents the variability of each ES indicator within the land-cover classes and do not give information about the reliability of the map, it has to be completed with an assessment of the general accuracy. 
One limitation of our study, underlined by the variable ability to scale-up field and locallyestimated ES data, is attributable to the presumed relationship between each indicator and landuse change. Upon summarizing local ES variations by coincident land-cover classes, first locally and then regionally, we implicitly but necessarily conflated variations in local ES supply with spatial variations in land-cover classes. Although land-cover change may underlie spatial variations for some ES indicators, it is possible, even likely, that this is not the case for other ES indicators. Variations in soil chemical quality index or soil water infiltration into soil rates are for example not particularly related to specific land-cover classes, at least in our study area. The species richness index, while impacted by land-cover change, is also influenced by other, related factors, such as landscape fragmentation. Soil carbon stocks were not meaningfully influenced by land cover changes in our study area (Le Clec'h et al. 2017) and would therefore prove very challenging to up-scale along lines explored here.

Moreover, a thematically detailed land cover classification is difficult to obtain at the regional level, provoking simplifications of the regional landscape and, ultimately, regional ES distributions. Tropical forest cover, for example, is highly heterogeneous in terms of structure, composition, and operation (Tuomisto, Linna, and Kalliola 1994; Guitet, Brunaux, et al. 2014). This is particularly true where anthropogenic forest cover such as woodlots, plantations, and fallows are conflated within a general 'forest' class, as they are by most global-scale land-cover classifications whose use might be attractive in the absence of regional land-cover maps. As a case in point, the GlobCover land-cover classification generically depicts much of Sumatra as 'closed broadleafed forest' (Bontemps et al. 2011), whereas much, perhaps most, of this cover is agroforestry, oil palm, or forest-agricultural mosaics not typically understood as 'forest' in the ecological sense (Dong et al. 2012; Miettinen, Shi, and Liew 2016). Such simplifications must be born in mind for any consideration of up-scaling approaches of the sort described here. Notwithstanding the unequal capacity to access reliable local spatial data for several ES indicators, at least three out of the four ES indicators considered here are coherent between regional and local scales.

We proposed a low-cost, reproducible method to map various ES indicators at regional scales. Our approach is a first step towards the systematic spatial characterization of ES at the regional scale. This was however only possible due to the ready availability of local-scale ES data to the authors. The replication and improvement of our approach in Brazil and elsewhere will ultimately depend on the support of scientific communities in providing localized, ideally systematically-gathered ES data. For instance, including more study sites with additional landcover types such as wetland or savannas and their associated ES values could help to improve our current maps. Also, a cooperation with as geomorphologists could help to data on forest diversity (Guitet et al. 2013; Guitet, Sabatier, et al. 2014). Such collaboration should help to refine the land-cover typology and improve our understanding of ES supply. Some international networks already monitor certain ES indicators, such as biomass (e.g., TmFO network, which monitors biomass change globally via 28 sites) or stored carbon (e.g., TEAM network, which estimates 
forest carbon for tropical forests). However, the large-scale monitoring of most ES indicators is arguably highly deficient (Skidmore et al. 2015). Such cooperation will almost certainly require a coordinating role by scientific institutions, such as herbaria or geographical societies, having interests in both local field work on the one hand and regional environmental change on the other.

\section{Conclusion}

Our study addresses four indicators of ES regulation and support in the Brazilian Amazon. This area is a rich ES hotspot but deforestation and forest degradation dynamics dramatically threaten most of these ES. To improve ES monitoring, protection, and management, maps of ES indicators at different spatial scales are required. Up-scaling approaches as presented here can bridge the gap between local and regional spatial scales, facilitating ES assessments at municipality or state levels. They may support conservation actions by efficiently identifying areas of diminishing ES provision, as well as by highlighting covariations amongst ES indicators.

\section{References}

Andriamahefazafy, F., C. Bidaud, O. Méral, G. Serpantié, and A. Toillier. 2012. 'L'introduction de la notion de service environnemental et écosystémique à Madagascar', VertigO - la revue électronique en sciences de l'environnement, 12.

Baccini, A., S. J. Goetz, W. S. Walker, N. T. Laporte, M. Sun, D. Sulla-Menashe, J. Hackler, P. S. A. Beck, R. Dubayah, M. A. Friedl, S. Samanta, and R. A. Houghton. 2012. 'Estimated carbon dioxide emissions from tropical deforestation improved by carbon-density maps', Nature Clim. Change, 2: 182-85.

Ball, G. H.and D. J. Hall, 1965. ISODATA, a novel method of data analysis and pattern classification. Technical report, DTIC Document.

Bangash, R., A. Passuello, M. Sanchez-Canales, M. Terrado, A. López, F. Elorza, G. Ziv, V. Acuña, and M. Schuhmacher. 2013. 'Ecosystem services in Mediterranean river basin: Climate change impact on water provisioning and erosion control', Science of The Total Environment, 458: 246-55.

Bierkens, M.F.P., P.A. Finke, and P. Willigeb. 2000. Upscaling and downscaming methods for Environmental Research. (Kluwer Academic Publishers: The Netherlands).

Bontemps, S., P. Defourny, E. Van Bogaert, O. Arino, V. Kalogirou, and J. Ramos Perez. 2011. "GlobCover 2009: Product description and validation report." In. Universite catholoque de Louvain: European Space Agency, .

Castro, M., and E. Fernández-Núñez. 2014. 'Soil properties and understory herbaceous biomass in forests of three species of Quercus in Northeast Portugal', Forest Systems.: 425-37.

Coelho, R. d. F. R., I. S. Miranda, and D. Mitja. 2012. 'Caracterização do processo sucessional no projeto de assentamento Benfica, sudeste do estado do Pará, Amazônia oriental. Boletim do Museu Paraense Emílio Goeldi. Ciências Naturais, 7.', Boletim do Museu Paraense Emílio Goeldi. Ciências Naturais,, 7.

Daily, Gretchen C., and Pamela A. Matson. 2008. 'Ecosystem services: From theory to implementation', Proceedings of the National Academy of Sciences, 105: 9455-56. 
Di Sabatino, Antonio, Luca Coscieme, Patrizia Vignini, and Bruno Cicolani. 2013. 'Scale and ecological dependence of ecosystem services evaluation: Spatial extension and economic value of freshwater ecosystems in Italy', Ecological Indicators, 32: 259-63.

Dong, Jinwei, Xiangming Xiao, Sage Sheldon, Chandrashekhar Biradar, Nguyen Dinh Duong, and Manzul Hazarika. 2012. 'A comparison of forest cover maps in Mainland Southeast Asia from multiple sources: PALSAR, MERIS, MODIS and FRA', Remote Sensing of Environment, 127: 60-73.

European Commission and Directorate-General for the Environment. 2013. "Mapping and assessment of ecosystems and their services an analytical framework for ecosystem assessments under action 5 of the EU biodiversity strategy to 2020." In, edited by Publication Office. Luxembourg.

Fearnside, Philip M. 2005. 'Deforestation in Brazilian Amazonia: history, rates, and consequences', Conservation biology, 19: 680-88. .2008. 'Amazon forest maintenance as a source of environmental services', Anais da Academia Brasileira de Ciências, 80: 101-14.

Finke, P. A., M. F. P. Bierkens, and P. de Willigen. 2002. "Choosing appropriate upscaling and downscaling methods for environmental research." In Agricultural effects on ground and surface waters: research at the edge of science and society. Wallingford (UK), IAHS, 2002. IAHS Publ. 273, pp, edited by J. H. A. M. Steenvoorden, F. Claessen and J. Willems.

Fisher, Brendan, R. Kerry Turner, Neil D. Burgess, Ruth D. Swetnam, Jonathan Green, Rhys E. Green, George Kajembe, Kassim Kulindwa, Simon L. Lewis, Rob Marchant, Andrew R. Marshall, Seif Madoffe, P.K.T. Munishi, Sian Morse-Jones, Shadrack Mwakalila, Jouni Paavola, Robin Naidoo, Taylor Ricketts, Mathieu Rouget, Simon Willcock, Sue White, and Andrew Balmford. 2011. 'Measuring, modeling and mapping ecosystem services in the Eastern Arc Mountains of Tanzania', Progress in Physical Geography, 35: 595-611.

Gerwing, J. 2002. 'Degradation of forests through logging and fire in the eastern Brazilian Amazon', Forest Ecology and Management, 157: 131-41.

Godar, J., E. Tizado, and B. Pokorny. 2012. 'Who is responsible for deforestation in the Amazon? A spatially explicit analysis along the Transamazon Highway in Brazil', Forest Ecology and Management, 267: 58-73.

Grêt-Regamey, Adrienne, Bettina Weibel, Kenneth J. Bagstad, Marika Ferrari, Davide Geneletti, Hermann Klug, Uta Schirpke, and Ulrike Tappeiner. 2015. 'On the Effects of Scale for Ecosystem Services Mapping', PLOS ONE, 9: e112601.

Grimaldi, M., J. Oszwald, S. Dolédec, M. Hurtado, I. de Souza Miranda, X. Arnauld de Sartre, W. Assis, E. Castañeda, T. Desjardins, F. Dubs, E. Guevara, V. Gond, T. Lima, R. Marichal, F. Michelotti, D. Mitja, N. Noronha, M. Delgado Oliveira, B. Ramirez, G. Rodriguez, M. Sarrazin, M. Silva, L. Costa, S. Souza, I. Veiga, E. Velasquez, and P. Lavelle. 2014. 'Ecosystem services of regulation and support in Amazonian pioneer fronts: searching for landscape drivers', Landscape Ecology, 29: 311-28.

Guitet, S., O. Brunaux, G. Jaouen, C. Richard-Hansen, S. Gonzalez, D. Sabatier, R. Pélissier, and N. Surugue. 2014. 'HABITATS : décrire et cartographier la diversité des forêts de Guyane', Rendez-vous Techniques - ONF, 43: 46-53.

Guitet, Stéphane, Jean-François Cornu, Olivier Brunaux, Julie Betbeder, Jean-Michel Carozza, and Cécile Richard-Hansen. 2013. 'Landform and landscape mapping, French Guiana (South America)', Journal of Maps, 9: 325-35. 
Guitet, Stéphane, Daniel Sabatier, Olivier Brunaux, Bruno Hérault, Mélaine Aubry-Kientz, JeanFrançois Molino, and Christopher Baraloto. 2014. 'Estimating tropical tree diversity indices from forestry surveys: A method to integrate taxonomic uncertainty', Forest Ecology and Management, 328: 270-81.

Hein, Lars, Kris van Koppen, Rudolf S. de Groot, and Ekko C. van Ierland. 2006. 'Spatial scales, stakeholders and the valuation of ecosystem services', Ecological Economics, 57: 209-28.

Higuchi, N., J. dos Santos, RJ. Ribeiro, L. Minette, and Y. Biot. 1998. 'Biomassa da parte aérea da vegetação da floresta tropical umida de terra-firme da Amazônia Brasileira', Acta Amazonica, 28: 153-66.

INPE Prodes. 2014. "Projeto Prodes Monitoramento da floresta Amazônica Brasileira por satélite." In.

Lacoste, Y. 1976. La géographie, ça sert d'abord à faire la guerre (Maspero.: France).

Lassabatere, Laurent, Rafael Angulo-Jaramillo, Jose Miguel Soria, Richard Cuenca, Isabelle Braud, and Randel Haverkamp. 2006. 'Beerkan Estimation of Soil Transfer Parameters through Infiltration Experiments-BEST', Soil Science Society of America Journal, 70: 521 à 32.

Le Clec'h, S., N. Jégou, T. Decaens, S. Dufour, M. Grimaldi, and J. Oszwald. 2017. 'From Field Data to Ecosystem Services Maps: Using Regressions for the Case of Deforested Areas Within the Amazon', Ecosystems.

Li, W., Z. Niu, Z. Y. Li, C. Wang, M. Q. Wu, and S. Muhammad. 2016. 'Upscaling coniferous forest above-ground biomass based on airborne LiDAR and satellite ALOS PALSAR data', Journal of Applied Remote Sensing, 10.

Liang, S. 2004. Quantitative Remote Sensing of Land Surfaces (Wiley: USA).

Liu, Shaomin, Ziwei Xu, Lisheng Song, Qianyi Zhao, Yong Ge, Tongren Xu, Yanfei Ma, Zhongli Zhu, Zhenzhen Jia, and Fen Zhang. 2016. 'Upscaling evapotranspiration measurements from multi-site to the satellite pixel scale over heterogeneous land surfaces', Agricultural and Forest Meteorology, 230: 97-113.

Marichal, R., M. Grimaldi, A. Feijoo M, J. Oszwald, C. Praxedes, D. Ruiz Cobo, M. del Pilar Hurtado, T. Desjardins, M. Silva Junior, L. Silva Costa, Iz. Miranda, M. Delgado Oliveira, G. Brown, S. Tsélouiko, Ma. Martins, T. Decaëns, E. Velasquez, and P. Lavelle. 2014. 'Soil macroinvertebrate communities and ecosystem services in deforested landscapes of Amazonia', Applied Soil Ecology, 83: 177-85.

Markewitz, D., E. Davidson, P. Moutinho, and D. Nepstad. 2004. 'Nutrient loss and redistribution after forest clearing on a highly weathered soil in Amazonia', Ecological Applications, 14: 177-99.

McInerny, Greg J., Min Chen, Robin Freeman, David Gavaghan, Miriah Meyer, Francis Rowland, David J. Spiegelhalter, Moritz Stefaner, Geizi Tessarolo, and Joaquin Hortal. 2014. 'Information visualisation for science and policy: engaging users and avoiding bias', Trends in Ecology \& Evolution, 29: 148-57.

Miettinen, Jukka, Chenghua Shi, and Soo Chin Liew. 2016. '2015 Land cover map of Southeast Asia at 250 m spatial resolution', Remote Sensing Letters, 7: 701-10.

Millennium Ecosystem Assessment, . 2005. Ecosystems and Human Well-being: Synthesis (Island Press: Washington DC).

Nahuelhual, Laura, Alejandra Carmona, Paola Lozada, Amerindia Jaramillo, and Mauricio Aguayo. 2013. 'Mapping recreation and ecotourism as a cultural ecosystem service: An application at the local level in Southern Chile', Applied Geography, 40: 71-82. 
Naidoo, Robin, and Taylor H. Ricketts. 2006. 'Mapping the Economic Costs and Benefits of Conservation', PLOS Biology, 4: e360.

Nelson, Bruce ., R. Mesquita, J. Pereira, S. Garcia Aquino de Souza, G. Teixeira Batista, and L. Bovino Couto. 1999. 'Allometric regressions for improved estimate of secondary forest biomass in the central Amazon', Forest Ecology and Management, 117: 149-67.

Pagella, Timothy F., and Fergus L. Sinclair. 2014. 'Development and use of a typology of mapping tools to assess their fitness for supporting management of ecosystem service provision', Landscape Ecology, 29: 383-99.

Pansu, M., and J. Gautheyrou. 2006. Handbook of soil analysis. Mineralogical, organic and inorganic methods (Springer: Germany).

Pelgrum, H. 2000. 'Spatial Aggregation of Land Surface Characteristics,' Wageningen University.

Potvin, C., P. Tschakert, F. Lebel, K. Kirby, H. Barrios, J. Bocariza, J. Caisamo, L. Caisamo, C. Cansari, J. Casamá, M. Casamá, L. Chamorra, N. Dumasa, S. Goldenberg, V. Guainora, P. Hayes, T. Moore, and J. Ruíz. 2007. 'A participatory approach to the establishment of a baseline scenario for a reforestation Clean Development Mechanism project', Mitigation and Adaptation Strategies for Global Change, 12: 1341-62.

Roche, P., I. Geijzendorffer, H. Levrel, and V. Maris. 2016. Valeurs de la biodiversité et systemes écosystémiques. Perspectives interdisciplinaires (Quae: France).

Sant, Eric D., Gregg E. Simonds, R. Douglas Ramsey, and Randy T. Larsen. 2014. 'Assessment of sagebrush cover using remote sensing at multiple spatial and temporal scales', Ecological Indicators, 43: 297-305.

Skidmore, A. K. , N. Pettorelli, N. C. Coops, G. Geller, M. Hansen, R. Lucas, and M. Wegman. 2015. 'Environmental science : agree on biodiversity metrics to track from space.', Nature, 523: 403-523.

Sumarga, E., and L. Hein. 2014. 'Mapping Ecosystem Services for Land Use Planning, the Case of Central Kalimantan', Environmental Management, 54: 84-97.

Swetnam, RD., B. Fisher, B. P. Mbilinyi, P. K. T. Munishi, S. Willcock, T. Ricketts, S. Mwakalila, A. Balmford, N. D. Burgess, A. R. Marshall, and S. L. Lewis. 2011. 'Mapping socio-economic scenarios of land cover change: A GIS method to enable ecosystem service modelling', Journal of Environmental Management, 92: 563-74.

Tuomisto, H., A. Linna, and R. Kalliola. 1994. 'Use of digitally processed satellite images in studies of tropical rain forest vegetation', International Journal of Remote Sensing, 15: 1595-610.

Ungaro, F., I. Zasada, and A. Piorr. 2014. 'Mapping landscape services, spatial synergies and trade-offs. A case study using variogram models and geostatistical simulations in an agrarian landscape in North-East Germany', Ecological Indicators, 46: 367-78.

van Berkel, D., and P. Verburg. 2014. 'Spatial quantification and valuation of cultural ecosystem services in an agricultural landscape', Ecological Indicators, 37: 163-74.

Velasquez, E., P. Lavelle, and M. Andrade. 2007. 'GISQ, a multifunctional indicator of soil quality', Soil Biology and Biochemistry, 39: 3066-80.

Wilbanks, T.J. 2006. 'How scale matters : some concepts and findings.' in WV. Reid, F Berkes , ., TJ. Wilbanks and D. Capistrano (eds.), Bridging Scales and Knowledge Systems, Concepts and Applications in Ecosystem Assessment.

Willemen, Louise, Peter H. Verburg, Lars Hein, and Martinus E. F. van Mensvoort. 2008. 'Spatial characterization of landscape functions', Landscape and Urban Planning, 88: 3443. 
Wu, H., and Z. Li. 2009. 'Scale Issues in Remote Sensing: A Review on Analysis, Processing and Modeling', Sensors (Basel, Switzerland), 9: 1768-93. 
Table 1. Ecosystem services metrics used in this study

\begin{tabular}{|c|c|c|c|c|c|c|}
\hline \multirow{2}{*}{ ES Indicator } & \multirow{2}{*}{$\begin{array}{c}\text { Unit or } \\
\text { measurement range }\end{array}$} & \multirow{2}{*}{ Ecosystem service } & \multicolumn{4}{|c|}{ Summary Statistics from Field Sites } \\
\hline & & & Міпітит & Махітит & Mean & $\begin{array}{l}\text { Standard } \\
\text { deviation }\end{array}$ \\
\hline $\begin{array}{c}\text { Vegetation } \\
\text { carbon stocks }\end{array}$ & Mg.ha ${ }^{-1}$ & Carbon density & 0 & 576 & 96 & 131 \\
\hline $\begin{array}{c}\text { Soil water } \\
\text { infiltration rate }\end{array}$ & $\mathrm{mm} \cdot \mathrm{h}^{-1}$ & $\begin{array}{c}\text { Water cycle } \\
\text { regulation and soil- } \\
\text { erosion control }\end{array}$ & 17 & 8862 & 1797 & 1888 \\
\hline $\begin{array}{l}\text { Soil chemical } \\
\text { quality index }\end{array}$ & 0.1 to 1 & $\begin{array}{l}\text { Soil stabilization } \\
\text { and agricultural } \\
\text { production }\end{array}$ & 0.1 & 1 & 0.4 & 0.16 \\
\hline Species Richness & 0.1 to 1 & $\begin{array}{c}\text { Biodiversity } \\
\text { maintenance and } \\
\text { conservation }\end{array}$ & 0.2 & 0.6 & 0.4 & 0.09 \\
\hline
\end{tabular}

Note: Summary statistics are for the three main field sites (Maçaranbuda, Pacajá and Palmares II)

Table 2: Confusion matrix of local (Landsat TM) and regional (MODIS) land-cover classifications.

\begin{tabular}{llll}
\multicolumn{4}{l}{ MODIS } \\
\hline Landsat TM & Forest & Transition area & Agricultural area \\
\hline Forest & 25 & 0 & 0 \\
Burned forest & 0 & 27 & 0 \\
Fallow land & 0 & 31 & 0 \\
Pasture with trees & 0 & 0 & 19 \\
Clean pasture & 0 & 0 & 17 \\
Bare soil & 0 & 0 & 14 \\
\hline
\end{tabular}

Note: values in the table represent 150 random points

Table 3: Independent measures of local ES provision used for validating regional ES estimates.

\begin{tabular}{|c|c|}
\hline Regional ES indicator & Independent dataset \\
\hline Vegetation carbon stocks & $\begin{array}{l}\text { Estimates by Baccini et al. (2012) combining co-located field measurements, } \\
\text { LiDAR observations, and MODIS imagery. }\end{array}$ \\
\hline $\begin{array}{l}\text { Rates of water infiltration } \\
\text { into the soil }\end{array}$ & $\begin{array}{l}\text { Cross validation of plot-level data for three main field sites (Maçaranduba, } \\
\text { Pacajá and Palmares II), with a random } 90 \% \text { of plots generating regional } \\
\text { estimates (training data) and } 10 \% \text { serving as the plot-level validation dataset. }\end{array}$ \\
\hline Soil chemical quality index & $\begin{array}{l}\text { Field data (Benfica, Pará). The sampling procedures were exactly the same } \\
\text { than for the three other sites. } N=\text { plots. }\end{array}$ \\
\hline Biodiversity index & $\begin{array}{l}\text { Cross validation of plot-level data for three main field sites (Maçaranduba, } \\
\text { Pacajá and Palmares II), with a random } 90 \% \text { of plots generating regional } \\
\text { estimates (training data) and } 10 \% \text { serving as the plot-level validation dataset. }\end{array}$ \\
\hline
\end{tabular}


Table 4. Summary of advantages and disadvantages of each of the validation approaches used in this study

\begin{tabular}{|c|l|l|}
\hline Validation approach & \multicolumn{1}{|c|}{ Advantages } & \multicolumn{1}{c|}{ Disadvantages } \\
\hline Field data-based validation & $\begin{array}{l}\text { Information about the general accuracy of } \\
\text { the map }\end{array}$ & $\begin{array}{l}\text { No detailed information about the } \\
\text { sources of uncertainties }\end{array}$ \\
\hline Local map-based validation & $\begin{array}{l}\text { Visual validation of the spatial structure } \\
\text { and overview of its simplification }\end{array}$ & Validation based on modeled data \\
\hline $\begin{array}{c}\text { Validation based on the } \\
\text { variability within the land-cover } \\
\text { classes }\end{array}$ & $\begin{array}{l}\text { Spatial information about the uncertainty } \\
\text { that should help to direct further research } \\
\text { (e.g. highlights needs for new } \\
\text { extrapolation data, more field data) }\end{array}$ & $\begin{array}{l}\text { Disconnected from the general } \\
\text { accuracy of the map. }\end{array}$ \\
\hline
\end{tabular}




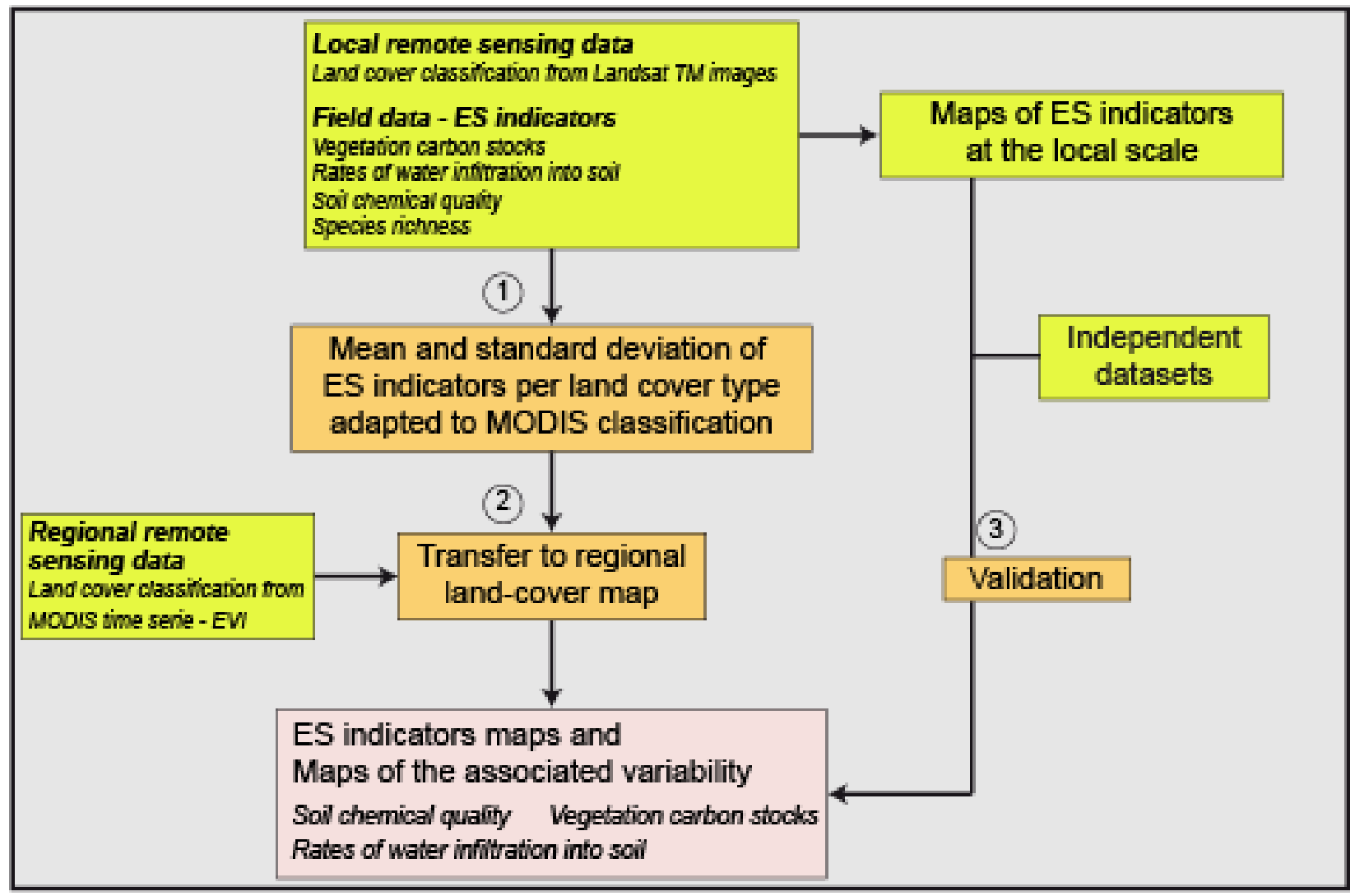

Figure 1. The three-stage methodological approach of for the regional representation of ES indicators. The local maps and the methodology used to produced them are presented in Le Clec'h et al. 2017 


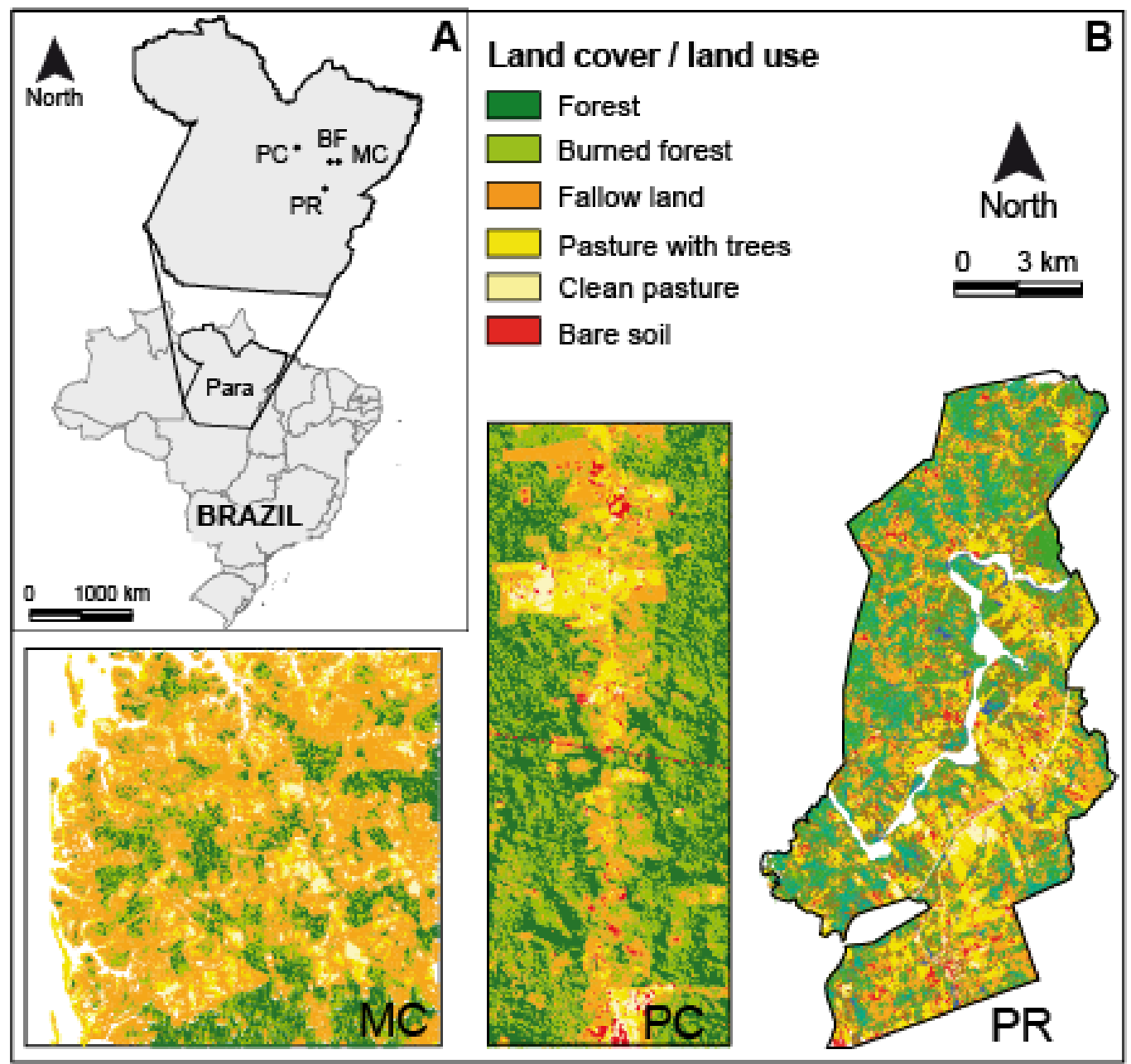

Figure 2. The State of Pará and local research sites. A: Pará State and its three local sites of Maçaranduba (MC), Pacajá (PC) and Palmares II (PR) and additional validation site, Benfica (BF). B: Land cover in in 2007 by site (Landsat TM). 


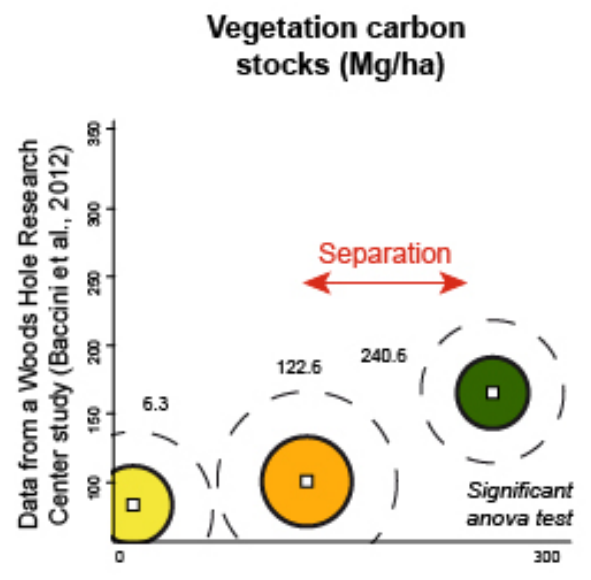

Mean values, predicted at the regional scale

\section{Chemical soil quality index}

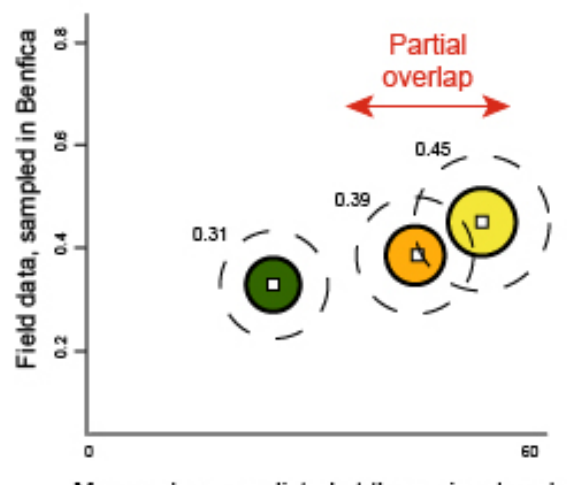

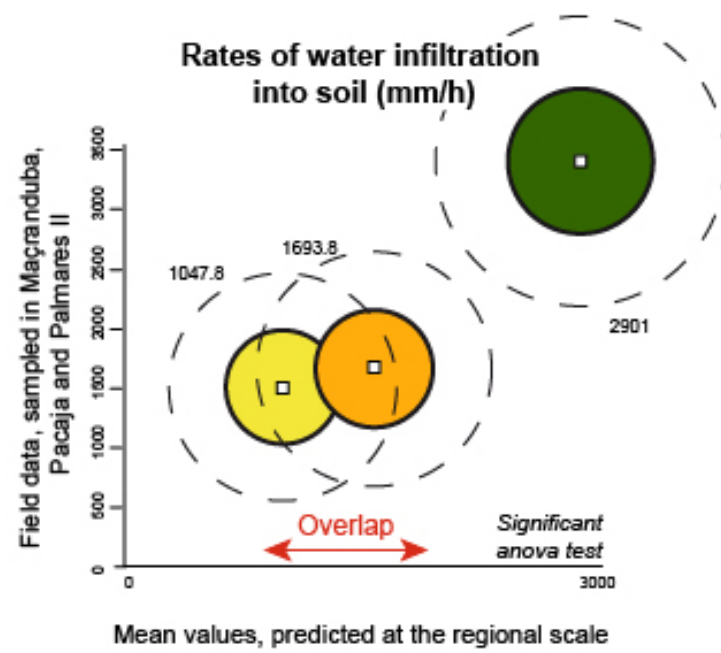

Standard

deviation $\times 2$

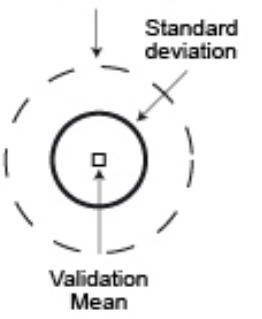

Species richness

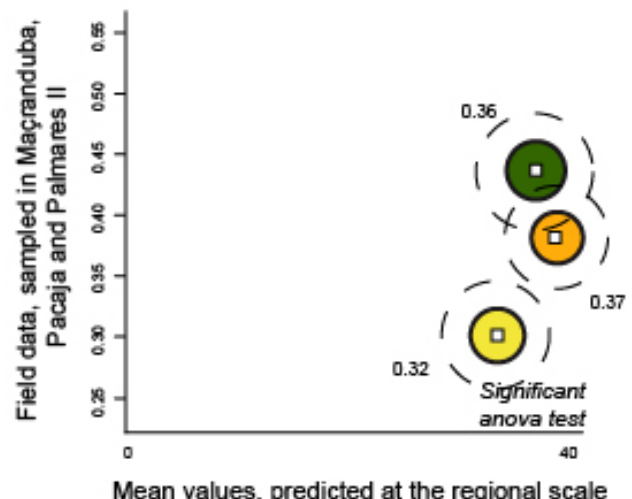

\section{MODIS land cover class}

Forest

Transition area
Agricultural area

Mean values, predicted at the regional scale

Mean values, predicted at the regional scale

Figure 3 - Agreement between the regional ES values and those of the independent datasets. The values for the validation data are displayed (y-axes) against the regional ES estimates for each class ( $x$-axes). The center of each circle corresponds to the mean values, for the validation data and regional estimates separately per regional land cover class. The circles around each mean correspond to the variability of the validation data within the land cover classes. The size of a circle is proportional to the standard deviation. The outer circles describe the range of two standard deviations. 


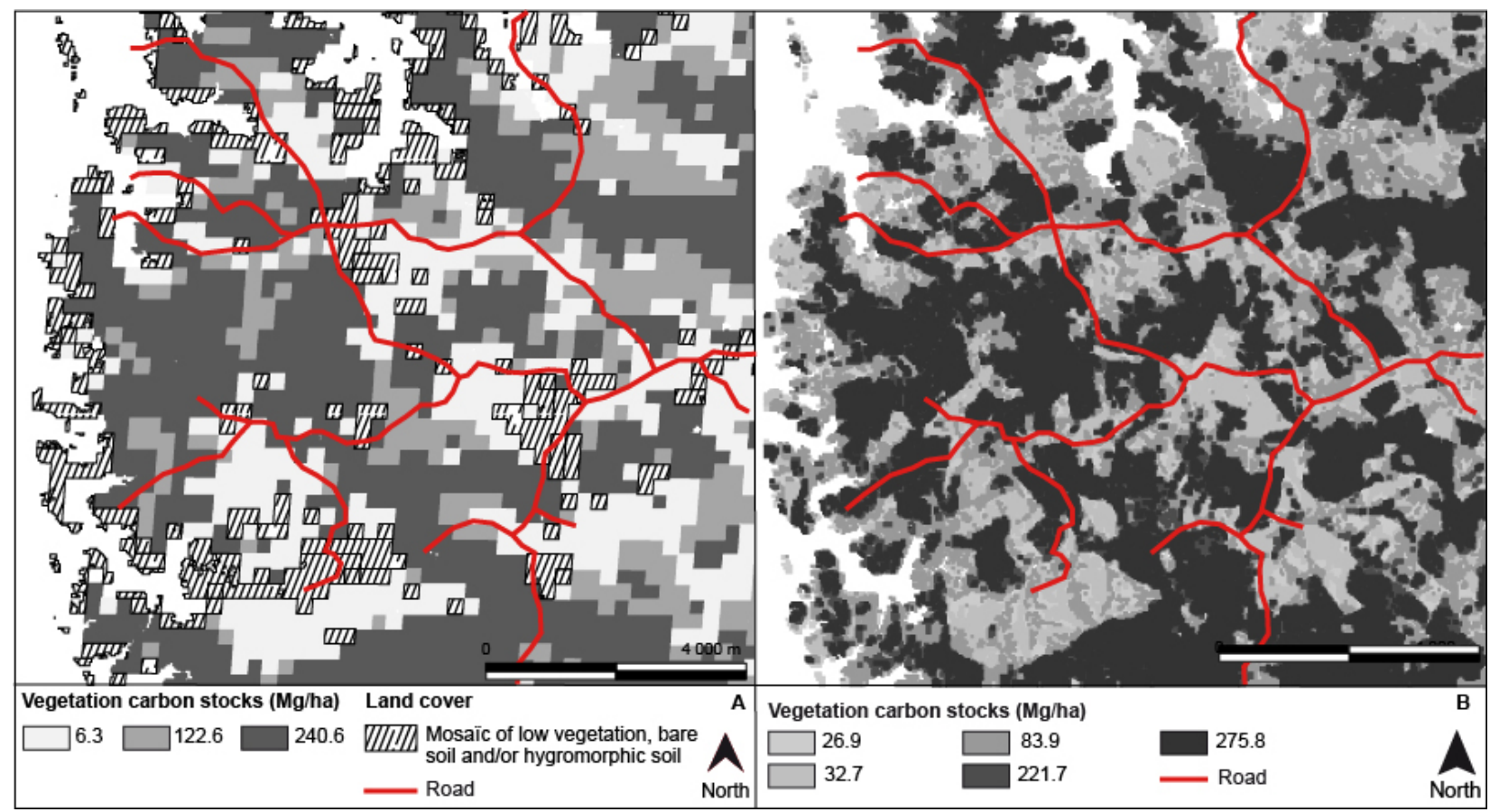

Figure 4.a. (A) Zoom of vegetation carbon stocks in Maçaranduba from the regional map based on MODIS land cover classification and (B) map resulting from the local model. Because Pará State has more land cover types than the local study sites (e.g. savannas or wetlands), we could not associate an ES value to the following land-cover types: mosaics of low vegetation and mosaics of bare soil, hydromorphic soils or wetlands. 


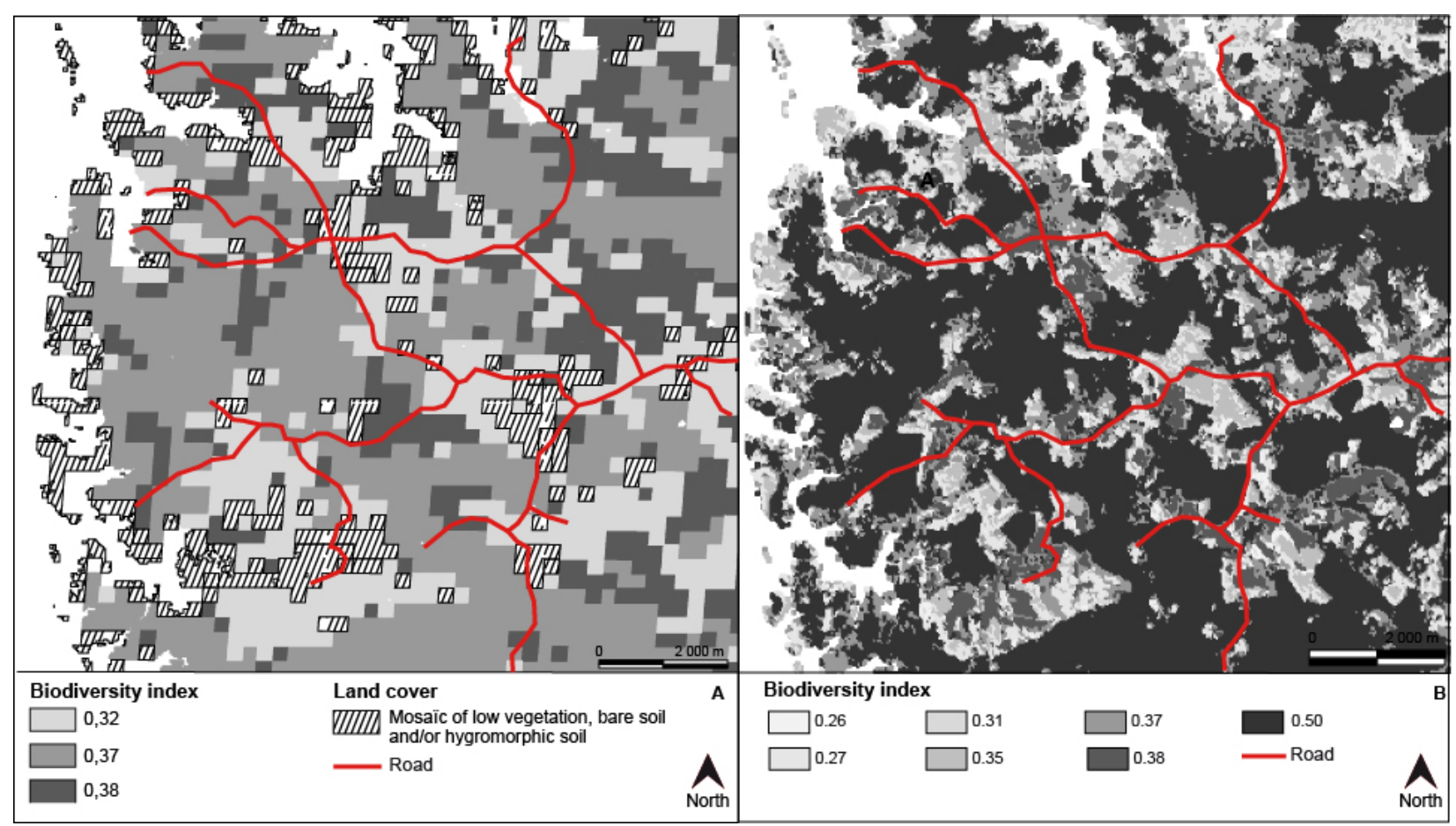

Figure 4.b (A) Zoom of the species richness index in Maçaranduba according to regional estimates based on MODIS land cover classification and (B) and locally-predicted estimates according to the local model. 


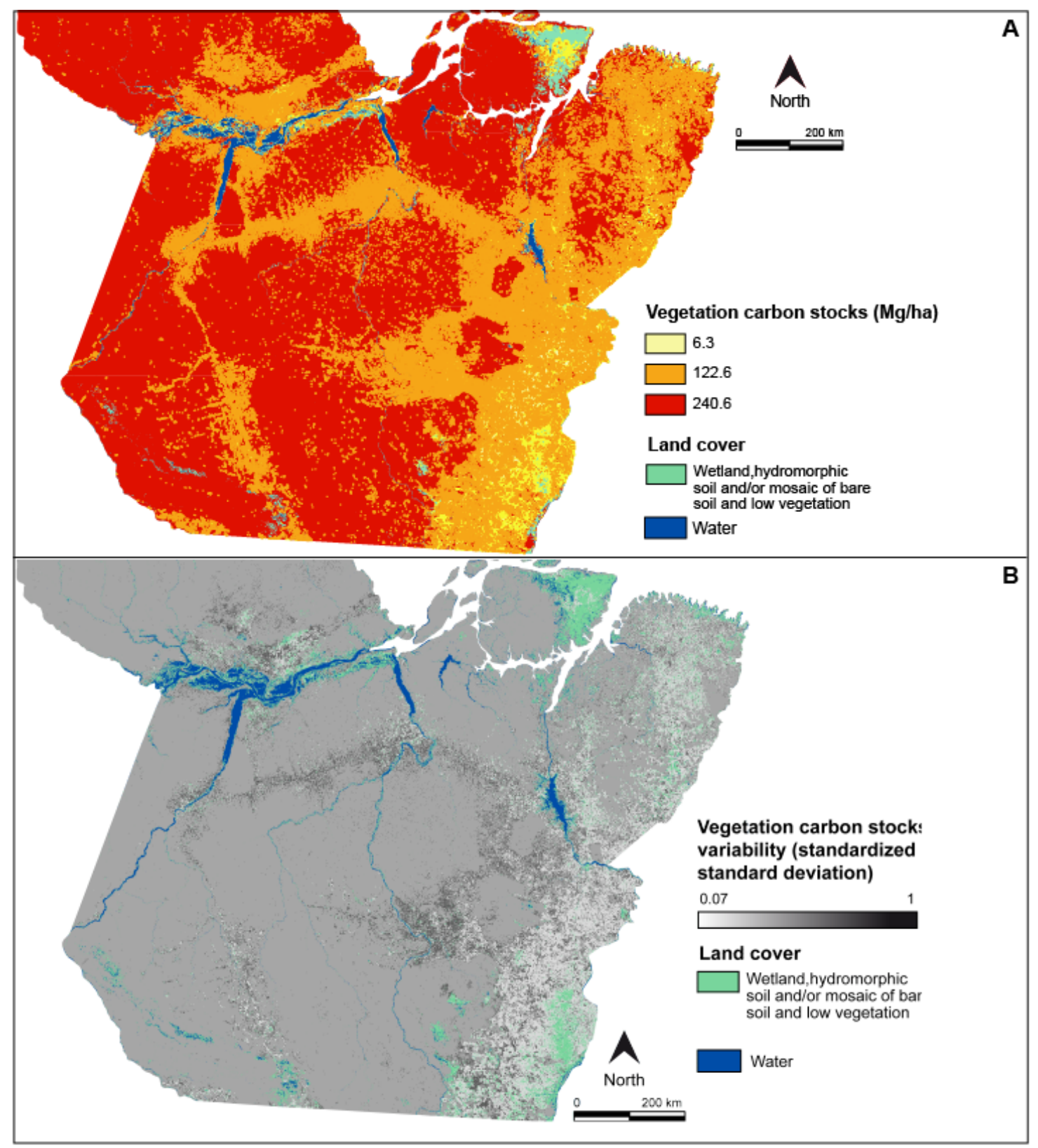

Figure 5.a. (A). Regionally-estimated vegetation carbon stocks in 2007 in Pará State, and (B). Variability (standardized standard deviation) of regionally-estimated vegetation carbon stocks within MODIS land-cover classes. A higher standard deviation means that vegetation carbon stocks are relatively variable within a land-cover class. 


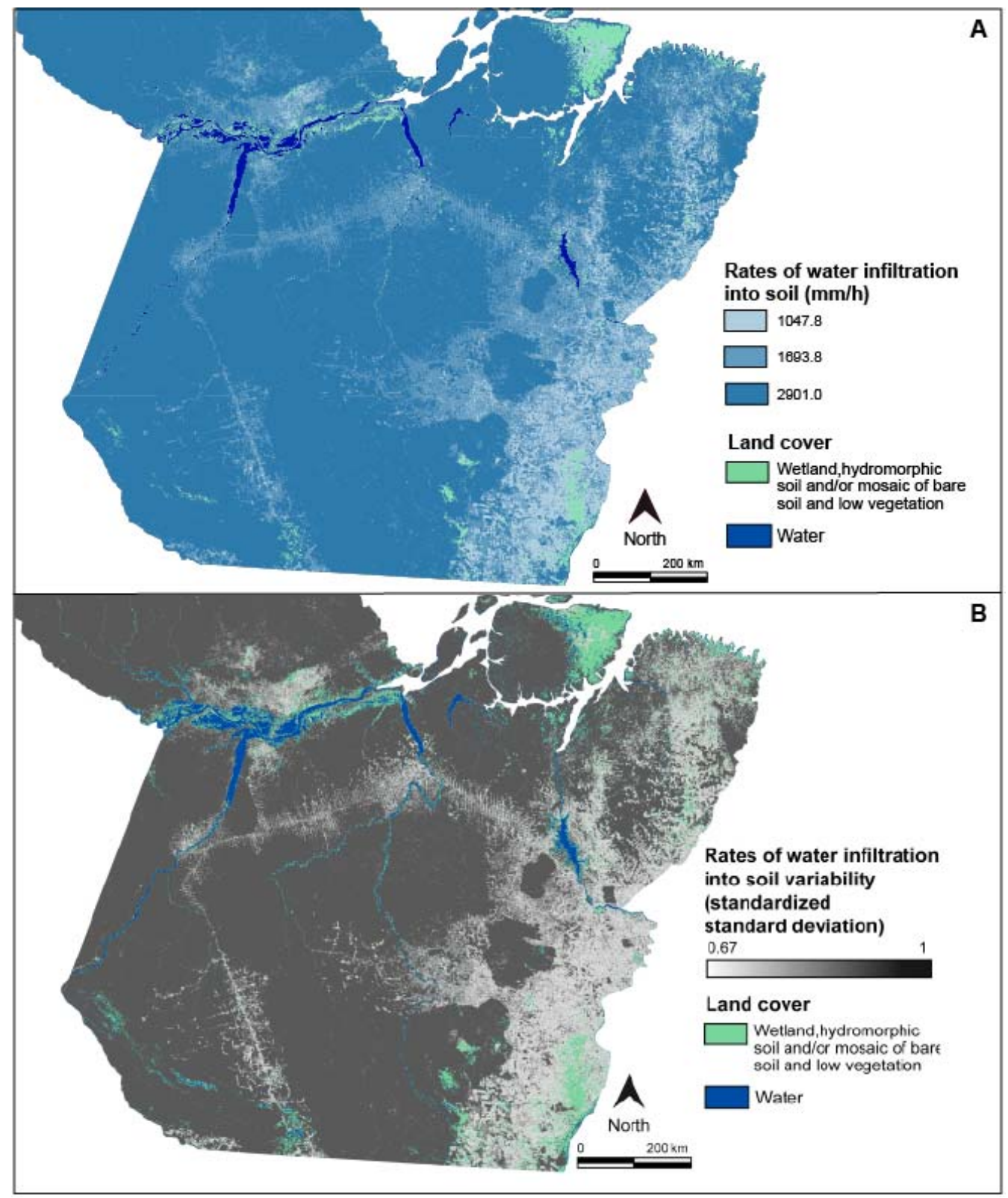

Figure 5.b. A. Regionally-estimated of soil water infiltration rate in 2007 in Pará State B. Regionally-estimated soil chemical quality index in 2007 in Pará State 